\title{
Flood Prediction at The Northern Region of UAE
}

\author{
Mohamed Elhakeem ${ }^{1, *}$ \\ ${ }^{1}$ Abu Dhabi University, Civil Engineering Department, P.O. Box 59911 Abu Dhabi, UAE
}

\begin{abstract}
Frequent flooding has been recently observed in the northern part of United Arab Emirates, particularly Ras Al Khaimah region (e.g., 2010, 2011 and 2016 floods). These frequent flood events raised the need for accurate estimates of surface runoff and possibly flooded areas in this region. Flooding is prevalent in this valley-coastal region due to the surrounding mountain stream network, which is characterized by flash floods from high precipitation amounts with high intensities between December and March. Most of the streams in this region have no hydraulic control structures at the outlets to regulate their flows. A hydrologic study was conducted at this urbanized valley-coastal area to identify the flood magnitudes and possible flooded areas using a number of geospatial, hydrologic and hydrodynamic models, namely GIS, HEC-SSP, Win-TR-20 and FESWMS. The study identified the flood magnitudes and possible flooded areas from large floods of return periods vary from 50 to 500 -year. FESWMS simulations showed that the flooded area increases for the 500-yr return period compared to the lower ones. The water depth ranges on average from 0.5 to $8.0 \mathrm{~m}$. Due to the natural slope of the simulated coastal area, higher depth was predicted, in general, close to the shoreline, while lower depth was predicted near the mountains.
\end{abstract}

\section{Introduction}

Frequent flooding has been recently observed in the northern part of United Arab Emirates (UAE), particularly Ras Al Khaimah region (e.g., 2010, 2011 and 2016 floods). These frequent flood events raised the need for accurate estimates of surface runoff and possibly flooded areas in this region. Flooding is prevalent in this valley-coastal region due to the surrounding mountain stream network, which is characterized by flash floods from high precipitation amounts with high intensities between December and March. Most of the streams in this region have no hydraulic control structures at the outlets to regulate their flows. A hydrologic study was conducted at this urbanized valley-coastal area to identify the flood magnitudes and possible flooded areas using a number of geospatial, hydrologic and hydrodynamic models, namely GIS, HEC-SSP, Win-TR-20 and FESWMS.

\footnotetext{
*Corresponding author: mohamed.elhakeem@adu.ac.ae
} 


\section{Study site}

The hydrologic study was conducted in an urbanized valley-coastal area located in Ras Al Khaimah region, United Arab Emirates (Fig. 1). The study area is about $176 \mathrm{~km}^{2}$ and is bounded with mountains from all sides except the north-west region, which is open to the Arabian Gulf Sea. A number of small towns and villages namely, Al Rams, Seih Al Birare, Qussaidat, Salhiyah, Fahlain, is located in the west side of the valley region. The boundary of the valley region is marked with red line in Fig. 1. On the eastern boundary of the valley, there are three main channels (Khors) namely, Wadi Biah, Wadi Al Beh, Wadi Najab, which contribute large amounts of surface runoff from their mountain watersheds to the valley-coastal region during severe storms. The three main channels are marked with orange lines in Fig. 1. Wadi Al Beh and Wadi Najab main channels end with large funnelshape sediment deposits in the valley-coastal region. The only exit for the surface runoff water from valley-coastal area is the north-west coastal area, which delivers the water to the Arabian Gulf Sea, marked with the red line at location number 11.

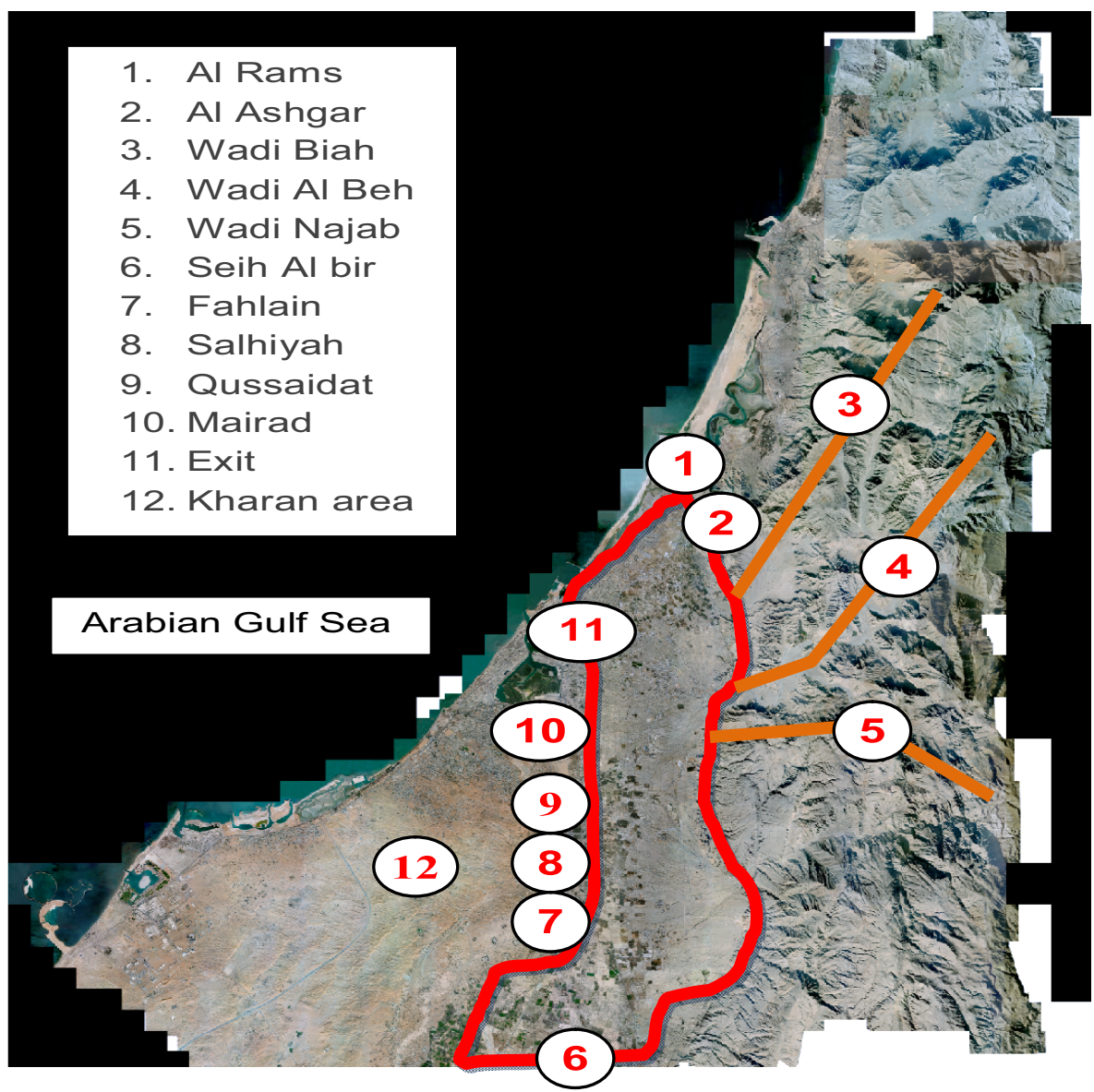

Fig 1. Aerial map of the study site location. 


\section{Results}

\subsection{HEC-SSP results}

Prior studies have indicated that individual events are important because the effectiveness of flood mitigating practices is best examined on single storm events [1]. Therefore, the daily rainfall data of Ras Al Khaimah for the period from 1984 - 2014 (31 year) were used in the Statistical Software Package (HEC-SSP) analysis to estimate the extreme events and their expected return period [2]. Table 1 shows the return period of different daily peak rainfall events. The extreme events ( $>50 \mathrm{yr}$ return period) were used in delineating of the flood areas of the study site.

Table 1. Return period of daily peak rainfall events of Ras Al Khaimah (1984 - 2014).

\begin{tabular}{|l|c|c|c|c|c|c|c|}
\hline Return period (yr.) & 2 & 5 & 10 & 50 & 100 & 200 & 500 \\
\hline Rainfall (mm) & 35 & 80 & 130 & 237 & 285 & 340 & 390 \\
\hline
\end{tabular}

\subsection{Win-TR-20 results}

The effective rainfall model Win-TR-20 [3, 4] was used to predict the surface runoff volumes and peak flow rates from the rainfall data obtained from HEC-SSP. Table 2 provides the peak runoff flow rates obtained from Win-TR-20 for the 3 watersheds contributing to the study area, namely, Wadi Biah, Wadi Al Beh, and Wadi Najab.

Table 2. Peak runoff flow rate of the 3 watersheds contributing to the study site under different return period.

\begin{tabular}{|l|c|c|c|c|c|c|c|}
\hline Return period (yr.) & 2 & 5 & 10 & 50 & 100 & 200 & 500 \\
\hline Watershed & \multicolumn{7}{|c|}{ Peak runoff flow rate $\left(\mathrm{m}^{3} / \mathrm{s}\right)$} \\
\hline Wadi Biah & 0 & 1.4 & 17.7 & 107.6 & 162.4 & 232.2 & 301.8 \\
\hline Wadi Al Beh & 0 & 14.3 & 143.2 & 989.3 & 1524.9 & 2186.4 & 2833.1 \\
\hline Wadi Najab & 0 & 13.4 & 109.4 & 675.5 & 1035.4 & 1462.8 & 1869.5 \\
\hline
\end{tabular}

\subsection{FESWMS results}

Due to the complex topography of the study area (Fig. 1), the 2D-hydrodynamic Finite Element Surface Water Modeling System (FESWMS) was used in the determining the flooded areas. FESWMS solves the differential forms of the continuity and the momentum equations in the stream wise and transverse directions using the Galerkin method of weighted residuals, providing water depth and depth-averaged velocity magnitude in $\mathrm{x}$ and $y$ directions at each node in the grid [5]. The governing equations are written in the conservative form hence, the momentum is conserved along the streamline and the model is capable of capturing shock effects [6]. The conservative form was chosen because of its robustness in solving critical and transcritical flow fields under both low and high flow conditions by allowing dry-elements to exist within the computational mesh [6]. FESWMS solves the following equations simultaneously:

$$
\frac{\partial z_{w}}{\partial t}+\frac{\partial q_{1}}{\partial x}+\frac{\partial q_{2}}{\partial y}-q_{m}=0
$$




$$
\begin{aligned}
& \frac{\partial q_{1}}{\partial t}+\frac{\partial}{\partial x}\left(\frac{q_{1}^{2}}{d}+\frac{1}{2} g d^{2}\right)+\frac{\partial}{\partial y}\left(\frac{q_{1} q_{2}}{d}\right)+g d \frac{d z_{b}}{\partial x}+ \\
& g n^{2} \frac{q_{1} \sqrt{q_{1}^{2}+q_{2}^{2}}}{d^{7 / 3}} \sqrt{1+\left(\frac{\partial z_{b}}{\partial x}\right)^{2}+\left(\frac{\partial z_{b}}{\partial y}\right)^{2}}-2 d \varepsilon_{x x} \frac{\partial^{2} \bar{u}}{\partial x^{2}}-\varepsilon_{x y} \frac{\partial}{\partial y}\left(\frac{\partial \bar{u}}{\partial x}+\frac{\partial \bar{v}}{\partial y}\right)=0 \\
& \frac{\partial q_{2}}{\partial t}+\frac{\partial}{\partial x}\left(\frac{q_{1} q_{2}}{d}\right)+\frac{\partial}{\partial y}\left(\frac{q_{2}^{2}}{d}+\frac{1}{2} g d^{2}\right)+g d \frac{d z_{b}}{\partial y}+ \\
& g n^{2} \frac{q_{2} \sqrt{q_{1}^{2}+q_{2}^{2}}}{d^{7 / 3}} \sqrt{1+\left(\frac{\partial z_{b}}{\partial x}\right)^{2}+\left(\frac{\partial z_{b}}{\partial y}\right)^{2}}-2 d \varepsilon_{y y} \frac{\partial^{2} \bar{v}}{\partial y^{2}}-\varepsilon_{y x} \frac{\partial}{\partial x}\left(\frac{\partial \bar{u}}{\partial x}+\frac{\partial \bar{v}}{\partial y}\right)=0
\end{aligned}
$$

where, (1) is the continuity and (2) and (3) are the momentum equations in $x$ and $y$ directions, respectively. In the equations, $t$ is time (s), $d$ is water depth (m), $\rho$ is water density $\left(\mathrm{kg} / \mathrm{m}^{3}\right), g$ is the acceleration due to gravity $\left(\mathrm{m} / \mathrm{s}^{2}\right), n$ is Manning's coefficient of roughness, $z_{w}$ and $z_{b}$ are water surface elevation and bed elevation above certain datum (m), $q_{1}$ and $q_{2}$ are the unit discharge fluxes $\left(\mathrm{m}^{2} / \mathrm{s}\right)$ defined as $\bar{u}_{d}$ and $\bar{v}_{d}$, respectively, $\bar{u}$ and $\bar{v}(\mathrm{~m} / \mathrm{s})$ are the depth-averaged velocities of an element in the stream wise and transverse directions, respectively, $q_{\mathrm{m}}$ is the resultant inflow or outflow from that element $(\mathrm{m} / \mathrm{s}), v_{x x}$ and $v_{y y}$ are the normal components of the eddy viscosity $\left(\mathrm{m}^{2} / \mathrm{s}\right)$ in the $x$ and $y$ directions, respectively, and $v_{x y}$ and $v_{y x}$ are the shear components of the eddy viscosity $\left(\mathrm{m}^{2} / \mathrm{s}\right)$ applied to the $x-y$ plane.

FESWMS inputs are the Manning's coefficient of roughness $n$, and the eddy viscosity $v$. Model inputs must be assigned correctly to represent the physical processes occurring in the model reach and to produce accurate model predictions. Manning's $n$ is an empirical coefficient that accounts for the total flow resistance caused by flow interaction with the boundary [7]. FESWMS utilizes Manning's $n$ to account for momentum loss due to bedshear, which may vary significantly in a stream reach in accordance to bed-bathymetry and roughness. The second input variable used by FESWMS is the eddy viscosity, $v$. Eddy viscosity accounts for flow resistance due to the internal shear stresses, or the Reynolds' stresses of the fluid incorporating the added energy dissipation due to turbulence in the flow [8]. Therefore, eddy viscosity is not a physical property of the fluid, but rather a turbulent characteristic of the flow. For isotropic flows in prismatic channels, a single eddy viscosity value is sufficient to describe the turbulence flow characteristics within the modelled reach.

The variation in the water depth of the coastal area was estimated from FESWMS with average Manning's value of 0.065 and eddy viscosity of $10 \mathrm{~m}^{2} / \mathrm{s}$ for all the simulations [5]. Fig. 2 shows the predicted water depth (flooding) from FESWMS simulations for different return periods. As expected, it can be seen that the flooded area increases for the 500-yr return period compared to the lower ones. Fig. 2 shows that the water depth ranges on average from 0.5 to $8.0 \mathrm{~m}$. Due to the natural slope of the simulated coastal area, higher depth was predicted, in general, close to the shoreline, while lower depth was predicted near the mountains. 


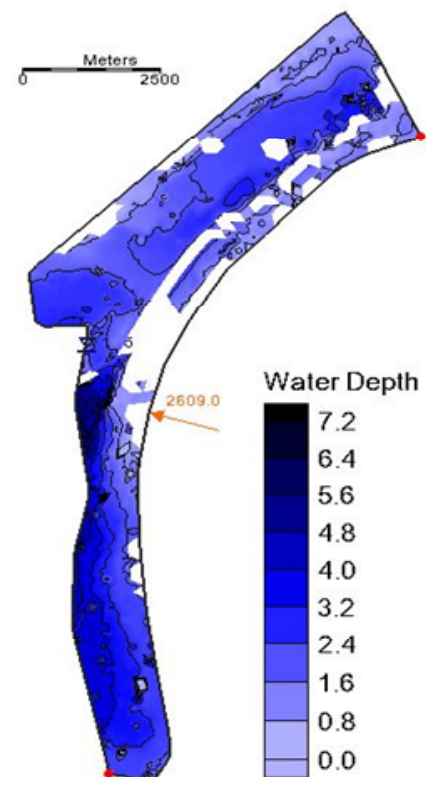

50 -yr return period

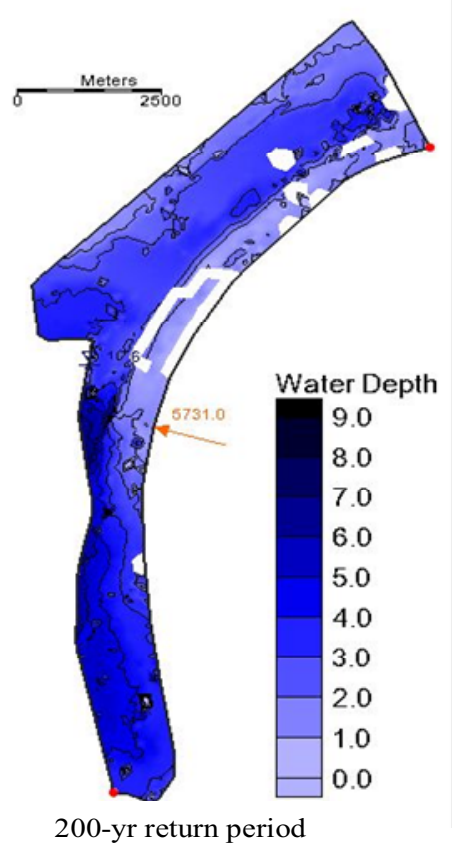

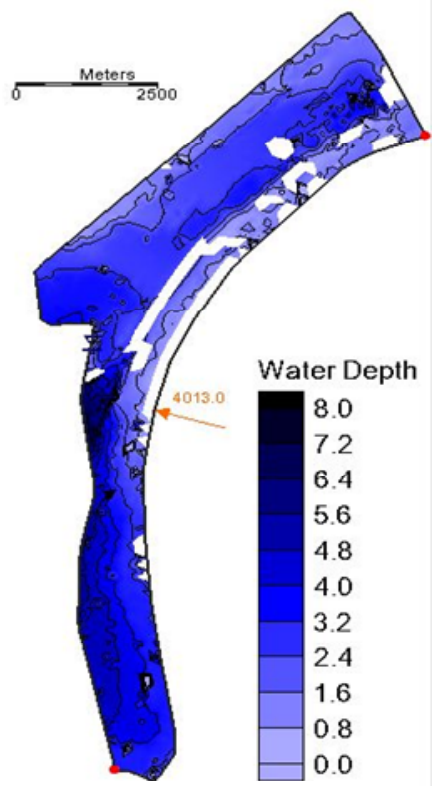

100 -yr return period

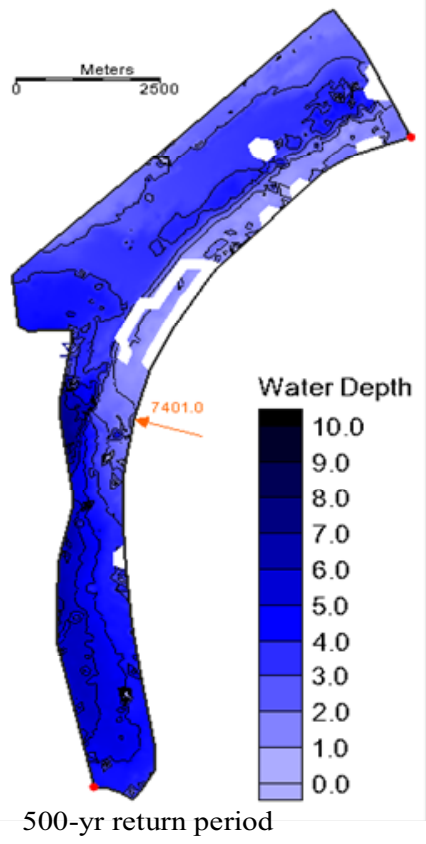

Fig 2. Predicted water depth at the coastal area under different return periods. 


\section{Conclusion}

This study presents a hydrologic study performed in an urbanized valley-coastal area located in Ras Al Khaimah region, United Arab Emirates. Runoff volumes and peak flow rates were quantified at study site using established hydrologic modeling techniques and software, namely HEC-SSP, Win-TR-20 and FESWMS. The study aimed at identifying the flood magnitudes and possible flooded areas from large floods of return periods vary from 50 to 500-year. FESWMS simulations showed that the flooded area increases for the 500 -yr return period compared to the lower ones. The water depth ranges on average from 0.5 to $8.0 \mathrm{~m}$. Due to the natural slope of the simulated coastal area, higher depth was predicted, in general, close to the shoreline, while lower depth was predicted near the mountains.

\section{References}

[1] M. Elhakeem and A.N. Papanicolaou, Estimation of the runoff curve number via direct rainfall simulator measurements in the State of Iowa, USA, Water Resources Management, 23(12), 2455-2473 (2009)

[2] U.S. Army Corps of Engineers, HEC-SSP User's manual (2007)

[3] Natural Resource Conservation Service (NRCS), WinTR-20 User's Guide (2004)

[4] R.H. McCuen, Hydrologic analysis and design, Prentice Hall, New York (2003)

[5] D. Froelich, User's manual for FESWMS Flo2DH (2002)

[6] M.H. Chaudhry, Open channel flow, Springer, New York (2008)

[7] D.M. Hicks and P.D. Mason, Roughness characteristics of New Zealand Rivers, New Zealand DSIR Marine and Freshwater Resources Survey, (1991)

[8] A.N. Papanicolaou and R. Hilldale, Turbulence characteristics in gradual channel transition, J. of Engineering Mechanics, 128(9), 948-960 (2002) 